\title{
LA PRODUCCIÓN DE ARMAS BLANCAS EN BILBAO DURANTE EL SIGLO XVI
}

POR

\author{
GERMÁN DUEÑAS BERAIZ
}

\section{RESUMEN - ABSTRACT}

Son escasas las noticias que poseemos sobre las zonas donde se fabricaban espadas en España. Uno de los centros más desconocidos es el de la ciudad de Bilbao, que desarrolló durante todo el siglo XVI, una importante producción de armas en parte destinadas a su exportación a las Islas Británicas. Gracias a una serie de documentos, entre los que figura uno inédito que recoge el pleito que los espaderos de Bilbao mantuvieron en 1569 con el Corregidor de Vizcaya, se han podido recoger algunos nombres y datos que permiten conocer más sobre la actividad de estos artesanos.

They are few notices published about swords manufacture in Spain during the $16^{\text {th }}$ century. One of the most unknown productions centers is the city of Bilbao, wich developed an important production of arms in part destined to its export to the British Islands. This article studies some documents, it is specialy interesting an unpublished document about the litigation hold up in 1569 between Bilbao swordsmiths and the «Corregidor» from Bilbao. Thanks of them it has been posible to compile names, marks and information about the activity of this craftsmen.

\section{PALABRAS CLAVE - KEY WORDS}

Bilbao. Bilbo. Espadas. Espaderos. Marcas. Moriscos.

Bilbao. Bilbo. Swords. Swordsmiths. Marks. Morish.

\section{INTRODUCCIÓN}

Aunque España es uno de los países en los que se cree hubo una importante producción de armas durante la Edad Moderna son escasos los trabajos publicados sobre el tema. Especialmente si nos centramos en el tema de las armas blancas, y más concretamente en el de las espadas.

Existen algunas referencias sobre diferentes zonas de fabricación armera, pero que no han sido objeto aun de estudios basado en el análisis de piezas y de un trabajo de archivo en profundidad, que nos permitan conocer realmente la importancia de los posibles enclaves productores.

Centrándonos en el tema de las armas blancas el centro más famoso del reino hispano, aunque no por ello mejor estudiado, es Toledo. Con respecto al resto sólo poseemos simples 
menciones indirectas ${ }^{1}$ como en los casos de Zaragoza, Valencia, Barcelona o Bilbao. A esta última ciudad y a los espaderos que en ella trabajaron se dedica el presente trabajo.

En primer lugar tenemos que aclarar que la zona geográfica que queremos abarcar en este estudio se centra exclusivamente en la ciudad de Bilbao, y su entorno más cercano. Por lo tanto no haremos referencias a las noticias y datos que sobre la producción de armas se realizaron en otras zonas del actual País Vasco. Decimos esto debido a que en la documentación de la época muchas veces nos encontramos referencias al término vizcaino, referido no sólo a la actual provincia de Vizcaya, sino que englobando a zonas más amplías que abarcaban prácticamente a las tres provincias vascas.

\section{LAS ESPADAS DE BILBAO}

La producción masiva de armas en la zona vasca se conoce desde la Baja Edad Media. Los Reyes Católicos también solicitaron armas, como por ejemplo con motivo de la lucha contra la armada turca y la defensa de Sicilia ${ }^{2}$.

Comisión a Diego de Soria para acopiar armas para proveer las fortalezas del reino de Sicilia, y la armada contra el turco, con preferencia a cualesquiera otros compradores, al precio corriente, mandando a los mercaderes que las tienen que las entreguen, y que en las ferrerías de Vizcaya, Guipúzcoa y Alava se labren, dejando toda otra labor.

Queda impresa en el negociado de Vizcaya. Num XX, Tomo I, fol. 83- Está rubricado

16 de diciembre de 1480

Existen varias referencias respecto a la fabricación de espadas en la villa de Bilbao. Hay que hablar en primer lugar de las fuentes literarias de los siglos XVI y XVII. En ellas se cita la existencia de las espadas de Bilbao ${ }^{3}$. Por ejemplo se habla de ellas en la obra Vida de Marcos de Espinel cuando se dice:

... y con esto me echó su bendición y me dió lo que pudo, y una espada de Bilbao, que pesaba más que yo, que en todo el camino no me sirvio más que de estorbo

También se cita una de estas armas en el Fénix de Salamanca, cuando en una refriega uno de los personajes al ir a desenvainar su espada exclama Tentemos la de Bilbao. En la novela burlesca El caballero Invisible se compara la rigidez de un muerto a través de la expresión se quedo como espada de Bilbao. O por último en la Monja Alférez, aunque esta vez haciendo una referencia más general, y quizás motivado por la rima se dice ante la proximidad de un combate:

Esto es hecho: allá va la vizcaina

Que nunca vuelve sin hacer cecina

También son citadas las espadas fabricadas en esta ciudad en los propios inventarios reales una espada dorada con una guarnición de unos seraphines con vayna de terciopelo negro: la hoja es de Bilbao, $1535^{4}$.

\footnotetext{
1 Leguina, 1898: 24.

2 González, 1829. Documento Num. XXIV, pág. 85.

3 Legarda, 1953.

4 Leguina, 1912: 386.
} 
Leguina también recoge en su obra sobre los maestros espaderos ${ }^{5}$ una cita sobre el tema cuando en 1588 se deja pasar a Juan de Anza y Hector de Loba hacia Flandes con doce hojas de espadas de Toledo y Bilbao para su uso.

Inventarios más concretos como por ejemplo el Inventario de Bienes y Joyas que dejó depositadas en el Archivo de Simancas Carlos V también reflejan la existencia de espadas bilbaínas. Concretamente en una cuenta de cargo de espadas en la que aparece una referencia a cinco hojas de espadas blancas hechas en Bilbao, que se tasaron en 850 maravedies, a precio de cinco reales cada una ${ }^{6}$.

Así mismo Larrañaga ${ }^{7}$ cita un documento existente en Simancas, en el que dos mercaderes solicitan en 1591 permiso para sacar de Guipúzcoa y Vizcaya 400 arcabuces y sus accesorios, así como 100 espadas de las de Bilbao, con destino a don Luis de Velasco, Virrey de Nueva España, para la sala de armas de la ciudad de México.

También encontramos referencias acerca de espadas originarias de esta parte del norte de España en documentos referentes a espaderos de otras partes de la Península Ibérica. Un claro ejemplo lo hayamos en uno de los puntos de las ordenanzas de espaderos de Segovia de $1536^{8}$ :

Otrossi que ninguno de los dichos oficiales pueda vender ni venda vayna de terciopelo de Toledo por de Granada ni de carnero por de cordovan e vecerro ni espada de una parte y lugar como de otra como de Bilbao por de Valencia e pissana por de Valencia de Bilbao e Toledo (...) so pena de averla perdido y seiscientos maravedies aplycados como dicho es

Son varias las conclusiones que de la lectura del presente punto de las ordenanzas de los espaderos segovianos podemos obtener. En primer lugar un pequeño listado de las principales ciudades productoras de espadas en la primera mitad del siglo XVI, y al mismo tiempo una jerarquía de calidades según el lugar donde se fabricaban, según la cual, las valencianas serían las más valoradas. Un segundo grupo lo formarían las realizadas en Bilbao y Toledo, y por último las menos valoradas serían las procedentes de la ciudad de Pisa.

Un segundo dato derivado del anterior es que en Castilla, y en esta fecha, la producción de espadas bilbaínas era conocida y valorada, hasta el punto de ser reconocidas por los espaderos segoviano, al mismo nivel que las toledanas.

En cambio los artesanos zaragozanos en la adicción a las ordenanzas de espaderos de 1602, alertaban sobre la práctica de hacer pasar espadas bilbaínas por toledanas, o por espadas realizadas por el espadero zaragozano Julián del Rey, prohibiendo dichas prácticas en la capital aragonesa:

\footnotetext{
Ittem estatuymos y ordenamos que persona alguna de qualquiere condicion sea no pueda revender ni revenda espadas, dagas ni otras cosas tocantes al dicho officio adereçadas ni por adereçar por vender como venden dichas espadas y dagas uno por otro vendiendolas por espadas toledanas siendo vizcainas y haziendo otras cosas en grande perjuycio y daño del bien publico y regimiento de la ciudad, vendiendo assi mesmo espadas vizcaynas con cruzes coloradas ${ }^{9}$ por de Julian, y con este color engañan a muchas personas con notable daño y perjuycio ${ }^{10} \ldots$
}

Se trataba de un negocio muy rentable; comerciantes y espaderos sin escrúpulos compraban espadas bilbaínas, de menor precio en el mercado, y les colocaban inscripciones y marcas toledanas o de Julián del Rey. De modo que las vendían por precios muy superiores al venderlas como espadas de más calidad. Esta práctica que resultaba común entre algunos

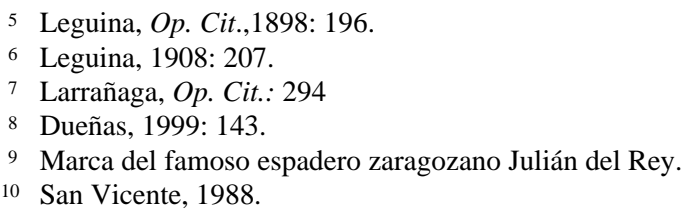


centros productores extranjeros respecto de las espadas toledanas, también, y tal como vemos, se practicaba dentro de la Península Ibérica, e incluso dentro de las mismas ciudades por espaderos de menor fama.

Pero estos maestros en el arte de forjar hojas de espada no sólo desarrollaron su trabajo dentro de los límites de la ciudad de Bilbao, y de sus alrededores, sino que se desplazaron a otras ciudades. Un ejemplo de esta movilidad geográfica es su presencia en otro importante centro productor de espadas peninsular del siglo XVI como era Sevilla. Muchos de los espaderos instalados en la capital andaluza eran originarios de Vizcaya, y concretamente de Bilbao.

Así se refleja en muchos de los datos aportados por Gestoso ${ }^{11}$ donde aparecen nombres de espaderos como los de Pedro de Lezama, Pedro de Munguía, Juan Palacios de Latasa, etc., todos ellos de origen vizcaíno. Otro ejemplo de la existencia de grupos de espaderos originarios de la zona vasca en Sevilla lo hallamos en un manuscrito que recoge Leguina ${ }^{12}$, titulado el Levantamiento de Sevilla y fechado en 1652. En él se da cuenta de una revuelta que se produjo en dicha ciudad, y en el transcurso de la cual los amotinados corren a proveerse de espadas y otras armas a los talleres situados en la calle de la Mar y de Vizcaynos.

Los descubrimientos y viajes que las naves españolas realizaron durante el siglo XVI necesitaban armas y equipos, algunos de ellos suministrados por la ciudad de Bilbao. Ejemplo de ello lo tenemos en los costes que tuvo la armada de Magallanes que se preparaba para realizar la primera vuelta al mundo. Entre las partidas de mercancías importadas desde Bilbao, figuran muchas armas de diferentes tipos como artillería (pasavolantes, falconetes, lombardas), armas defensivas (petos, capacetes, barbotes, etc.), armas de fuego (50 escopetas), dardos, lanzas, chuzos, y también seis hojas de espadas que con un coste de 680 maravedis fueron tomadas por el Capitán ${ }^{13}$.

\section{LAS ESPADAS BILBAÍNAS E INGLATERRA}

Las espadas de Bilbao tenían como principal mercado el abastecimiento de la propia ciudad y sus alrededores. Otra parte se destinaría a la exportación, tanto al resto de la Península Ibérica, como a otras zonas del extenso imperio bajo el control de la monarquía hispánica, como por ejemplo América.

Creemos además que otro de los destinos más importantes de esta producción fueron las Islas Británicas. El comercio de los puertos vizcainos con las islas es de sobra conocido por los historiadores. Entre los productos con los que se comerciaba estaban las espadas. Incluso existía una tipología de espadas que hoy en día desconocemos y que se hacían al gusto de los compradores.

Ejemplo de ello es el contrato que se hizo entre el espadero bilbaíno Martín de Gorosabel y el comerciante de Lequeitio Pascual de Hormaegui en agosto de 1519. Por este documento el primero se compromete a entregar al segundo en el mes de marzo del siguiente año doscientas ocho espadas anchas de la suerte que se acostumbran de hacer para Irlanda ${ }^{14}$.

Otra prueba de la relación de los espaderos bilbaínos con las Islas Británicas la encontramos en la presencia de las armas por ellos forjadas en la literatura de la época. Un autor de la relevancia de Shakespeare menciona a los «bilbos» o espadas de Bilbao en una de sus obras, concretamente en las Alegres Comadres de Windsor ${ }^{15}$. En ella Falstaff para escapar de

11 Gestoso, 1899: 254.

12 Leguina, Op. Cit.: 76.

13 Guiard, 1905: 201.

14 Areitio, 1959: 133

15 No tenemos que confundir estos bilbos, con los también llamados así y que consistían en unos grilletes, que deberían su nombre probablemente a estar realizados también por el hierro vizcaíno. Shakespeare también hace referencia 
un marido celoso se esconde dentro de una cesta de ropa sucia en una posición muy incomo$\mathrm{da}^{16}$. Por ello dice que se sintió doblado como una espada que junta la punta con la empuñadura like a good bilbo, es decir como la de una buena bilbo. Esta obra, estrenada entre los años 1599 y 1600, indica la presencia en la Inglaterra de finales del XVI de unas espadas denominadas «bilbos» que poseían una aguzada punta para el uso de estoque y una hoja muy flexible.

Esta cita podría hacer alusión a uno de los métodos que utilizaban los espaderos para demostrar la calidad y flexibilidad de las hojas, y sobre todo de una de las técnicas usadas por los forjadores de hojas para descubrir los posibles defectos en la misma, y que eran denominados «pelos».

Cabe preguntarse cuál es el significado concreto de este término de «bilbo». En primer lugar tenemos que decir que se trata del nombre que la ciudad de Bilbao recibe en el idioma de los vascos. Respecto a su relación con el mundo de la espadería algunos autores británicos consideran directamente a los «bilbos» como un tipo de espada de las que denominan «rapiers», roperas, de un menor tamaño ${ }^{17}$. Otros, en cambio ${ }^{18}$, piensan que hace referencia a un tipo de guarnición de origen español desarrollada durante la segunda mitad del siglo XVII y que era conocida en las Islas Británicas por «bilbo». Dicha guarnición, que se relaciona con la tipo «Papenheimer», está formada por dos grandes conchas vueltas hacia el puño, que a veces presentan decoraciones cinceladas en su exterior, con aro guardamano y gavilanes.

Reid también le da un tercer significado, sin descartar los anteriores. Este, haría alusión a un tipo de espada diferente y más antigua que recibía el mismo nombre en la Inglaterra de 1592.

Shakespeare nace el 23 de abril de 1564 y fallece el mismo día del año de 1613. Esto hace improbable que se refiera a la empuñadura tipo «bilbo», debido a que como hemos dicho anteriormente aparece con posterioridad a la muerte de Shakespeare y mucho después de que fuera escrita la obra en la que menciona dicho término. Hace además clara referencia a un arma completa, descartando así que se refiera sólo a un tipo de empuñadura.

Por lo tanto existiría un tipo de arma anterior, tal y como dice Reid, de origen bilbaíno conocida y extendida en el mercado inglés de finales del siglo XVI.

Hoy en día el término «bilbo» se utiliza para identificar algunas espadas existentes en colecciones y museos británicos. Este es el caso de la Royal Armouries de Leeds donde en sus inventarios son muchas las espadas que son denominadas como «bilbos», a veces haciendo referencia a la guarnición «Sword steel hilt of Bilbo type» (Inv. IX.69) o «Sword Hilt of Bilbo type» (Inv. IX. 70). O de una manera más general: «Spanish bilbo sword» (Inv. IX.1364); «Cavalry sword bilbo type» (Inv. IX. 1777) ${ }^{19}$.

Hemos de llamar la atención especialmente sobre la primera de ellas (Inv. IX. 69). En el catálogo de la colección de la Torre de Londres $^{20}$, se dice de esta espada tipo «bilbo» que posee en su hoja la inscripción LECARA. Sin duda alguna hace referencia a la inscripción con la que firmaba el espadero Pedro de Lezama, quien según la grafía de la época colocaba su apellido LEÇAMA, con c cedilla (Ç) para el sonido de la zeta, aunque no se aprecie el rabillo de esta letra en las inscripciones troqueladas ${ }^{21}$. Así aparece en varias espadas fabricadas por este espadero como la existente en la Armeria Reale de Torino (Inv. G 180), o en el Museo Poldi Pezzoli de Milán (Inv. 656) con la inscripción PEDRO DE/ LECAMA en el vaceo de la hoja.

\footnotetext{
a los mismos en su tragedia Hamlet (acto quinto, escena cuarta) cuando el príncipe danés expresa como se siente comparádose a los presos con grilletes y sentiame peor que los amotinados en los bilbaos.

16 Concretamente en su acto III, escena V, v. 115.

17 Ffoulkes, 1912: 155.

18 Reid, 1976: 143.

19 Debo estos datos a la amabilidad del Conservador Jefe del Departamento de Armas dela Royal Armouries Mr. Graeme Rimer.

20 Ffoulkes, 1916: 269.

21 Varias de las espadas atribuidas a este espadero aparecen firmadas de la misma forma, concretamente.
} 

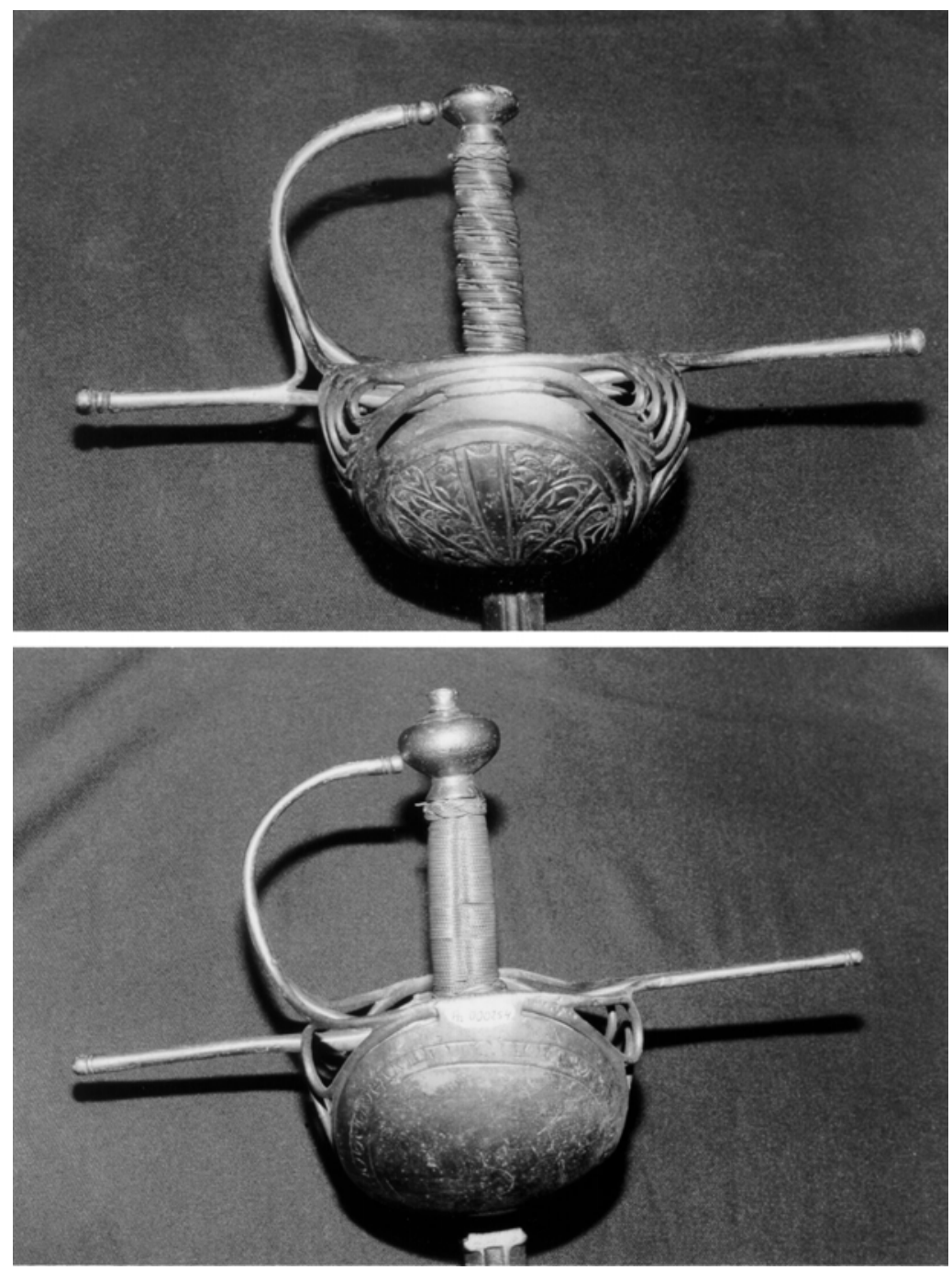

Fig. 1. Dos guarniciones de espadas de las denominadas Bilbos en Inglaterra existentes en el Museo San Telmo de San Sebastián (H-000254 y H-000243).

La toponimia del nombre indica claramente su origen vizcaíno ${ }^{22}$. Palomares ${ }^{23}$ lo recoge en su nómina con el número 84, asignándole una marca que consiste en una $\mathrm{P}$ coronada inscrita en un escudete. Añade que trabajó en Sevilla, además de en Toledo. Su relación con la capital andaluza parece confirmarse al aparecer un Pedro de Lezama, vizcaino estante en Sevilla firmando un contrato como ayudante del maestro de hazer espadas Maese Cosme Vilar en $1559^{24}$. El mismo autor recoge un tal Pedro de Lisana (sic), que podría tratarse del mismo espadero, en los autos de elección de veedor del gremio de espaderos en 1610. Por lo

22 Lezama es una población vizcaína cercana a Bilbao.

23 Nómina de los últimos, y mas famosos armeros de Toledo, que labraron Espadas hasta la entrada del presente Siglo XVIII en que acabó esta Fábrica (Dueñas, 2000: 270).

24 Gestoso, Op. Cit.: 25. 
tanto también podría establecerse una relación directa entre hojas realizadas por espaderos bilbaínos y las guarniciones «bilbos».

Algunos autores ${ }^{25}$ creen que el origen de este término data del siglo XVIII, debido a la cantidad de espadas que salían desde el puerto de Bilbao hacia América y Holanda. La llegada a Inglaterra de este tipo de guarniciones y su denominación se produjo debido al acercamiento que hubo hacia España por parte de la política de Jacobo I. Está claro que el uso del término «bilbo» referido a un tipo de guarnición es bastante anterior, tal y como lo demuestra la cita de Shakespeare antes comentada

Nosotros creemos en cambio que el origen de este término era diferente. Debió referirse en un principio a espadas de hoja ancha y de dos filos fabricadas en Bilbao para el mercado inglés a principios del siglo XVI. Posteriormente las hojas y las guarniciones evolucionaron y el contacto con el mercado inglés continuó, aplicándose el término de «bilbo» al nuevo tipo de espada que llegaba desde Bilbao.

Por último creemos que está justificado decir que los citados «bilbos» no eran sólo espadas fabricadas con hierro bilbaíno en tierras inglesas, como sin duda también se hizo. Ni que aludieran exclusivamente a un tipo de guarnición, aunque hoy en día sea con lo que más se identifica este término. Existió por tanto un mercado en las Islas Británicas para las espadas forjadas y manufacturadas por los espaderos bilbaínos ya desde el siglo XVI.

En el siglo XVI los precios de las espadas que salían del puerto de Bilbao hacia tierras inglesas, entre otros destinos, eran de 303 maravedis la docena de paños de espadas, 150 maravedis por cada daga dorada y 100 sin dorar. También se exportaban espadas de armas y conteras de espadas, estas últimas a 150 la gruesa ${ }^{26}$.

\section{LAS MARCAS DE LOS ESPADEROS DE BILBAO}

A la hora de catalogar una hoja como española es usual el recurso a inscripciones que hacen referencia a la ciudad de Toledo o a algunos de los espaderos recogidos por Palomares. En el caso de las marcas y de los punzones también nos encontramos con un fenómeno parecido. Solamente se indica una posible producción española cuando son marcas que recuerdan a las reproducidas por Palomares, o cuando son iniciales inscritas en escudetes coronados.

Por ello consideramos muy interesante una relación de espaderos y sus correspondientes marcas existentes en el Archivo Municipal de Bilbao. Esta relación aparece concretamente en el Libro del Concejo de diciembre de $1524^{27}$. En ella se recogen nueve nombres de espaderos bilbaínos y un total de doce marcas. Los nombres de los espaderos son: Juan de Vidaguren, Pedro de Zamudio, Martín de Gorocibay, Martín de Ugarte, Martín de Mantulis, Domingo de Azcoitia, Juan de Olagorta y Martín Ochoa de Achuri. El motivo de esta diferencia entre el número de nombres y de marcas se debe a que dos de los espaderos poseían varias marcas, dos en el caso de Juan de Olagorta, y hasta tres Domingo de Azcoitia.

En el caso de Domingo de Azcoitia se da la circunstancia de que existe una diferencia de nombres entre los dos autores que hacen referencia a esta lista. Uno de ellos ${ }^{28}$ cita a Domingo de Azcoitia junto a tres marcas, mientras que el segundo ${ }^{29}$ nombra dos espaderos diferentes: Domingo de Alcorta y Juan de Azcoitia. Pensamos que Areitio usa el nombre del prime-

25 Oakeshott, 1980:169.

26 Guiard, Op. Cit. pag. 527.

27 Archivo Histórico Municipal de Bilbao. Libro del Concejo. Año 1524. El primero que llama la atención sobre dichas marcas es Guiard, aunque el que más y mejores datos recoge sobre ellas es Areitio, ya que reproduce las mismas.

28 Areitio, Op. Cit.

29 Guiard, Op. Cit. 
ro y el apellido del segundo, debido quizás a una difícil lectura de ambos nombres, provocando que de dos espaderos diferentes obtenga uno ${ }^{30}$.

Esta aclaración resulta muy necesaria debido a la existencia de una espada en el Museo de 1'Hermitage (Inv. Z.O. 1710) ${ }^{31}$ que posee en la hoja la siguiente inscripción: JOANES DE ASCOITIA/ IN TE DOMINE SPERAVI. A la hora de hablar de las espadas españolas existentes en dicho museo, esta espada es tratada antes que el conjunto de espadas de lazo y taza. Esto nos lleva a pensar que se trate de una pieza anterior en el tiempo, posiblemente de comienzos del XVI, y que por tanto pudo ser realizada por el Juan de Azcoitia citado por Guiard en el documento de 1524. Otro espadero de mismo nombre y apellido aparece en el pleito con el corregidor de Bilbao de 1569, y del que hablaremos posteriormente, en sus personas a francisco de azcoitia y juan su hijo espaderos.

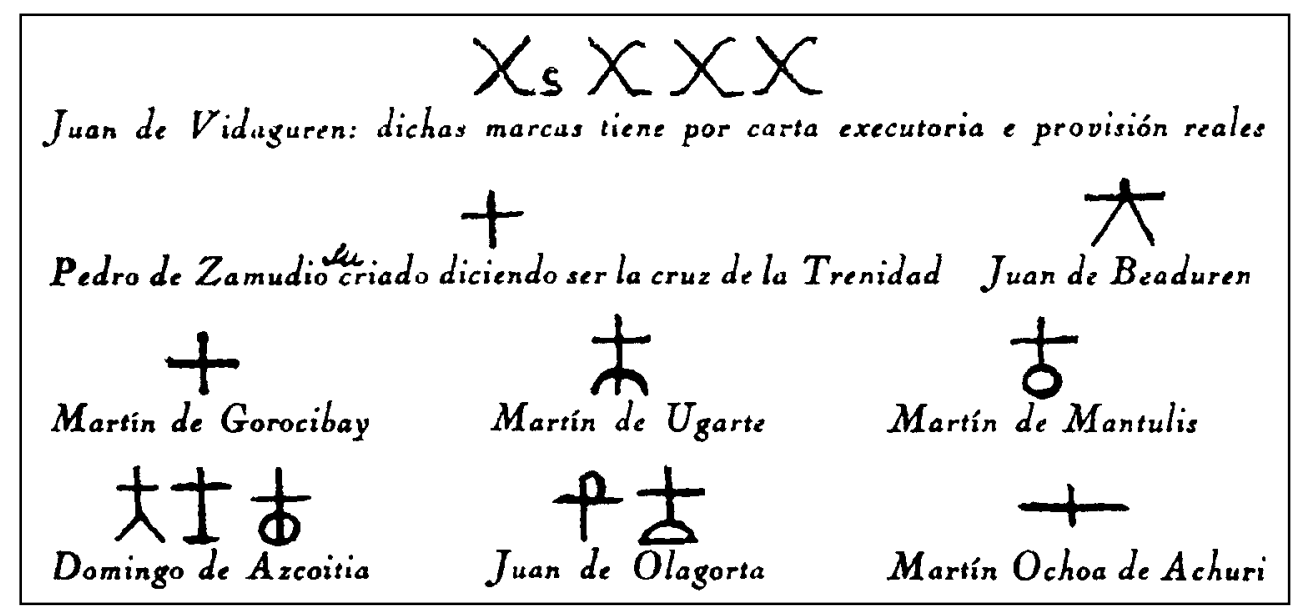

Fig. 2. Marcas que usaban los espaderos de Bilbao existentes en el libro de Concejo de Bilbao de 1524 según Dario de Areitio.

Leguina $^{32}$ también cita una espada en la que aparece la inscripción IOANNES EN BIL$\mathrm{BAO}$, y cuya marca era una $\mathrm{V}$ cruzada, aunque no cita a que espada se refiere.

Tenemos que destacar el hecho de que las marcas que aparecen en el Libro del Concejo de Bilbao de 1524 tienen muy poco que ver con las que normalmente se vienen atribuyendo a las usadas por los espaderos de Toledo y por extensión españoles. Son en su mayoría diferentes versiones de cruces, y que según Guiard ${ }^{33}$, tienen mucho parecido con las que los comerciantes de la ciudad solían marcar las sacas de lana.

$\mathrm{Si}$ vemos la relación de marcas comerciales usadas en Bilbao durante el último tercio del siglo XVI recogidas por Guiard ${ }^{34}$ y las comparamos con las existentes en varias espadas existentes en colecciones británicas, hallaremos parecidos importantes. Como por ejemplo con la marca existente en una espada de la Royal Armouries de Leeds (Inv. IX. 52), (Fig. 3).

\footnotetext{
30 A pesar de los intentos por corroborar estos datos en las fuentes ha sido imposible por la situación actual del Archivo Municipal de Bilbao.

31 Miller, 1995: 187.

32 Leguina, Op. Cit.

33 Guiard, Op. Cit.

34 Ibidem.
} 
Que las marcas recogidas en el Libro del Concejo de Bilbao son cruces, no sólo está claro después de su examen, sino que además uno de ellos, concretamente Pedro de Zamudio, explicó el significado de su simbología debajo de la misma, diciendo ser la cruz de la trenidad. Además este artesano se identifica como criado del anterior, Juan de Vidaguren. El término criado hay que entenderlo aquí como oficial ${ }^{35}$ en el taller del maestro espadero titular.

El oficial formaba parte del segundo escalafón dentro del gremio. Aparecía desempeñando su trabajo en el taller de un maestro siendo ya conocedor suficiente del arte, esperando tener el dinero y la experiencia suficiente para acceder al puesto de maestro. A pesar de que tenemos pocos datos sobre la duración y circunstancias en las que se desarrollaba la vida del oficial, algunos autores consideran que se dio un aumento gradual de los plazos de permanencia, tanto en el aprendizaje como en el oficialato.

En la situación de oficial, a priori, ya se cobraba un jornal pagado por el maestro. Aunque todavía se estaría recibiendo un sueldo en especie en forma de conocimientos, lo que hacía que el dinero recibido no fuera excesivamente alto. Según las ordenanzas de espaderos por nosotros estudiadas los oficiales no podían establecerse por libre, no podía poner tienda o taller sin haber sido examinado de maestro espadero por parte de las autoridades gremiales ${ }^{36}$.

Los espaderos de Bilbao daban gran importancia a sus marcas. Juan de Vidaguren es un buen ejemplo de ello, ya que debajo de ellas señaló que las poseía por carta executoria e provision reales. Es decir las poseía estando avaladas por documentos oficiales de la más alta instancia.

Veamos ahora el contenido del documento que acompaña a las marcas de los espaderos de Bilbao. El origen de este documento queda perfectamente explicado por el Síndico en una sesión anterior que el Concejo de la ciudad de Bilbao celebró el 26 de septiembre de 1524. Estaba destinado básicamente a controlar los abusos que se producían en el comercio y producción de espadas.

Estos fraudes se producían gracias a que algunos espaderos falsificaban, contrahacían, las marcas de otros espaderos de la ciudad; utilizaban las de otros de más renombre, el uno toma la muesca del otro; o simplemente le quitaban a la espada una marca y le colocaban otra, mudaban las marcas.

Las autoridades municipales decidieron intervenir para tratar de evitar estos engaños, tanto para sus conciudadanos como para los compradores del exterior. Esta actuación se tradujo en que cada espadero eligiera una sola marca, ya que también la duplicidad de marcas era práctica común, y que se registrara en un libro del Concejo, al lado del nombre del espadero, fruto de lo cual es el documento de diciembre de ese mismo año. El resultado de esta preocupación municipal fue el documento que contenía las marcas.

El objetivo de esta medida también lo recogen los promotores de la misma, que no era otro que el de evitar el descrédito de los buenos oficiales, y que fueran más y mejor conocidos estos artesanos.

Las penas a las que debían atenerse los espaderos presentes y futuros que desarrollasen su actividad artesanal tanto en la villa como en los arrabales, en caso de contravenir esta ordenanza, consistía en la consabida pena económica, 5000 maravedís, de los cuales el cincuenta por ciento iría a parar a la cofradía que los espaderos de Bilbao tenían en la Iglesia de Santiago. Así mismo serían desterrados a cuatro leguas de la villa, no pudiendo volver a ejercer su oficio.

A la muerte de un espadero si algún hijo u oficial suyo quisiera seguir utilizando la marca del difunto debería de ponerlo en conocimiento del concejo. Siendo las penas en caso con-

35 Hemos de señalar que en el siglo XVI se utiliza el término oficial como la persona que ejerce un oficio en general, sin especificar si se trata de un maestro o un oficial.

36 Dueñas: $O p$. Cit. 
trario también en dinero y en caso de carecer del mismo, recibir cien azotes y ser posteriormente exhibido a lomos de un asno por la ciudad para su pública vergüenza.

La explicación de este punto la encontramos en el hecho de que en muchas ocasiones y debido a la fama de la calidad de las hojas realizadas por algunos espaderos, se seguían marcando hojas con su nombre o marcas por parte de otros espaderos, a veces por sus oficiales o aprendices, con objeto de vender su producto a un precio superior en el mercado.

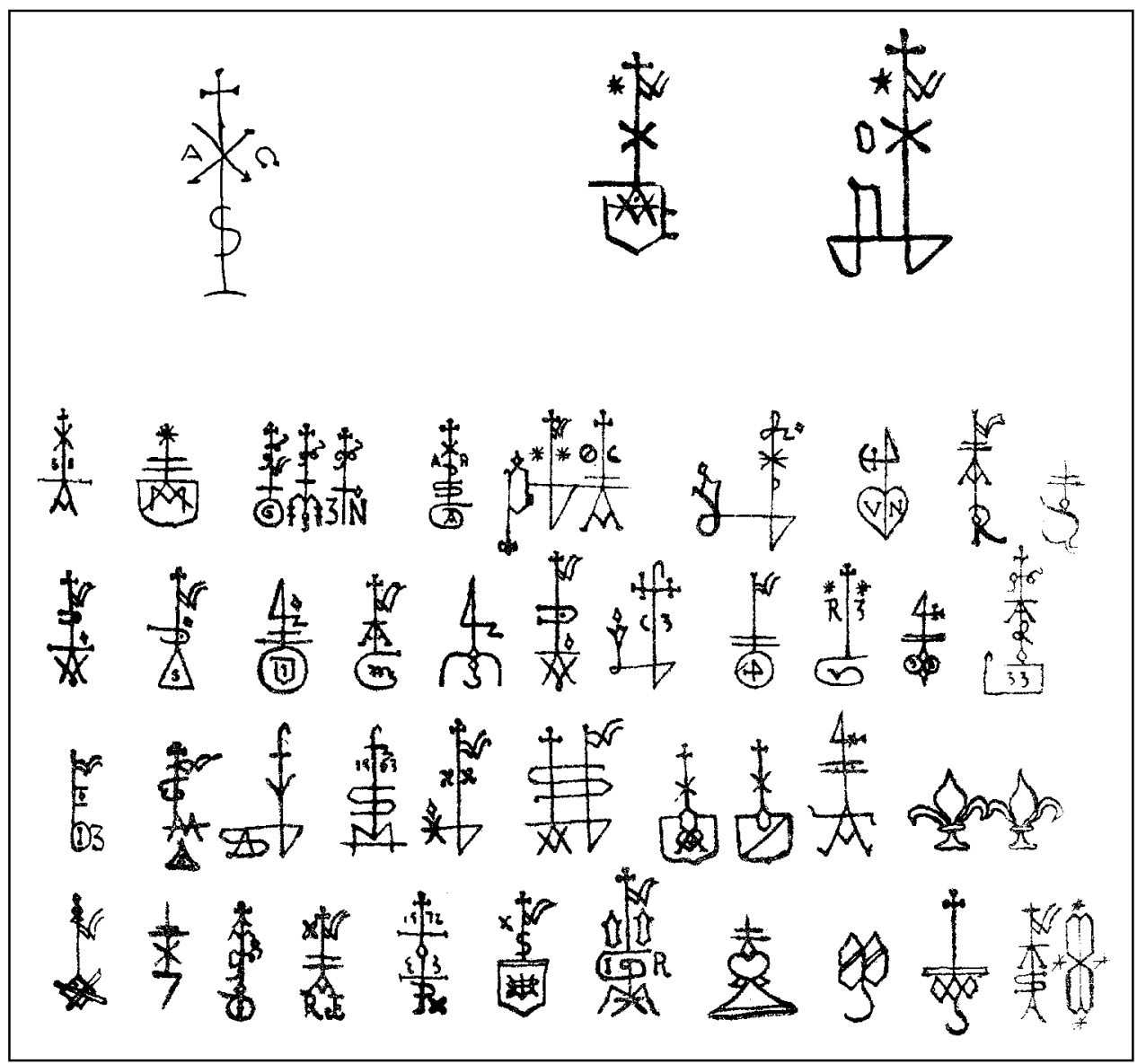

Fig. 3. Comparación entre la marca de la espada IX. 52 (parte superior izquierda) de la Royal Armouries de Leeds, y las de varios comerciantes de Bilbao del siglo XVI recogidas por Guiard.

Las disputas por la posesión de estas marcas podían llevar incluso a pleitos y enfrentamientos, incluso dentro del mismo núcleo familiar como en el caso del famoso espadero de Zaragoza Julián del Rey ${ }^{37}$.

La práctica que se producía en Bilbao de poseer varias marcas, y contrahacer las de otros más famosos, iba en contra de lo que se buscaba con la adjudicación de una marca a cada espadero, es decir la perfecta identificación de cada autor de espadas. Para ello debían de 
utilizar una sola marca, la que habían mostrado a la autoridad municipal durante toda su vida profesional. Sabemos que ésto no se respetaba produciéndose fraudes, falsificando las marcas de espaderos famosos, tanto de la misma ciudad como de otros centros importantes como Zaragoza, Segovia o Toledo, tal y como vimos anteriormente.

El poco éxito de estas medidas lo hallamos a finales del siglo XVI. Concretamente en el capítulo 68 de las ordenanzas municipales de Bilbao de $1593^{38}$, en la que prohibe esta práctica, no sólo a los espaderos:

Otrossi dijeron que ordenavan y ordenaron y mandaron, que todos los oficiales espaderos, puñaleros, cuchilleros, cereros, puchereros que labran estaño, y otros qualesquier oficios que tienen por costumbre de poner sus marcas en las obras que hazen sean obligados a usar de la marca que tienen mostrada a la Iusticia y Regimiento y lo la puedan mudar ni usar de otra marca ni señal alguna sopena de cada tres mil maravedis por cada vez aplicados a tercios para los reparos juez y denunciador y que los oficiales que de nuevo pusieren tiendas sean obligados a acudir a la dicha Iusticia y Regimiento y dar su marca y pedir licencia para usar de ella y de otra manera no la pongan son la misma pena

Por lo tanto vemos una vez más la voluntad de las autoridades municipales respecto de la producción, calidad y honradez de armas blancas realizadas en Bilbao. Esto indica la intención de impedir los fraudes a través de cambios de marcas, y llevar un estricto control de las marcas y sus propietarios. También nos informa de que a finales del siglo XVI se seguían marcando las espadas producidas en Bilbao.

A mediados del siglo XVI, y gracias a una relación de participantes en un alarde ${ }^{39}$ que tuvo lugar en $1558^{40}$ tenemos un segundo listado de los espaderos que trabajaban en Bilbao. En él aparecen los siguientes espaderos: Juan de Baquio, Pedro de Urizar, Anton de Hereño, Francisco de Azpeitia, Iñigo de Sertucha, Hernando de Gastaca, Juan de Becurten, Jacobo de Achuri, Juan de Bolumburu, Juan de Achuri, Juan de Barraucu, Martin de Zabala, Martin de Izcoa, Juan de Jauregui y Martin de Zamudio. Un total de quince artesanos.

Los ejemplos de piezas marcadas con cruces y la producción de espadas en Bilbao son escasos. Uno de los más claros es el de una espada existente en la colección del Museo de l'Ármée (Inv. J.130). Esta presenta en su recazo una marca en forma de cruz griega, mientras que la inscripción que aparece en el vaceo de la hoja dice «VIVA BISCAIA» ${ }^{41}$, en clara referencia a la provincia vasca de la que es capital Bilbao.

La primera referencia de espadero que hubiera trabajado en la villa de Bilbao la realiza Palomares $^{42}$ en su nómina. Allí recoge el nombre de Pedro de Lagaretea de quien dice que trabajó en la capital vizcaina además de en Toledo. A pesar de lo que Palomares señala, la presencia de este espadero está localizada en una zona no muy lejana como era Tolosa, donde también existían numerosas fraguas dedicadas a la fabricación de espadas. Aparece primero en abril de 1578, como representante de los espaderos de Tolosa en un pleito para conseguir permiso para poder vender espadas a los habitantes de la zona, sin tener que ser examinadas por el veedor que era el representante de la corona encargado, de velar por la calidad de las armas allí producidas ${ }^{43}$. Posteriormente un tal Pedro de Elcaraeta, nuevamente como representante de los espaderos de Tolosa, forma parte en unas pruebas que se hicieron en abril de 1586 para contrastar la calidad de los aceros de Mondragón y Tolosa ${ }^{44}$. Por últi-

38 Ordenanzas Municipales de la Villa de Bilbao, 1593.

39 Los alardes consistían en ejercicios militares por parte de la población civil para que en caso de ser necesitada estuvieran ellos y sus armas preparados para actuar como fuerza de choque.

40 Guiard, Op. Cit.: 201

41 Boccia, Godoy, 1986.

42 Palomares, 1762.

43 Múgica, 1910: 78.

44 Larrañaga, Op. Cit.: 472. 
mo decir que su nombre no aparece citado en ninguno de los listados de espaderos bilbaínos aquí recogidos hasta 1569 .

Pensamos que se trata del mismo espadero que aparece en Tolosa, ya que la firma que posee la pieza del Museo San Telmo de San Sebastián demuestra la facilidad con la que la inscripción de su apellido ha podido ser leída de diferentes maneras como Laraeta, Gareta, etc. Esto se debe a que en el vaceo de una de las hojas escribe con grafía del siglo XVI PEDRO DE (usando la contracción de las dos letras) EL, mientras que en el otro lado de la hoja aparece ARAETA.

Conocemos además la existencia de varias espadas firmadas por él en diferentes museos europeos como la del Musée National de Cluny, procedente de la colección Debruges, firmada con la inscripción PEDRO GARETA (sic) ME FECIT; la del Musée de l'Armée de París $^{45}$, en la Rüstkammer de Dresde (Inv. No 267$)^{46}$, y la del Museo San Telmo de San Sebastián (Inv. H-000258) ${ }^{47}$.

\section{EL PLEITO CON EL CORREGIDOR DE VIZCAYA}

Además de estas referencias y de los documentos que hacen referencia a la presencia de espaderos en la villa de Bilbao en 1524 y en el alarde de 1558 arriba mencionado, el documento que pasamos a analizar es quizás la prueba más clara de la existencia y pujanza de estos espaderos en el siglo XVI.

Se trata de un documento judicial en grado de apelación a la Sala de Vizcaya de la Chancillería de Valladolid, fechado el 9 de diciembre de $1569^{48}$. Este pleito tenía como protagonistas al Corregidor del Señorío de Bilbao y las Encartaciones el licenciado Juan Doballe de Villena por una parte y a los espaderos de la villa de Bilbao de la otra. El motivo de dicho pleito no era otro que el de la prohibición por parte del Corregidor a los espaderos bilbaínos de realizar ventas de espadas y dagas a personas forasteras sin la licencia del corregidor.

En la primera página del pleito aparecen, la fecha, los contendientes y el motivo de la querella entre ambas partes:

Pleito

9 de agosto de 1569

De los espaderos de la villa de Bilbao con el Corregidor de Vizcaya sobre que no vendan espadas para fuera del rreyno sin su licencia. Firman como representantes de los espaderos Francisco de Azcoitia y Juan de Achuri

Corregidor del Señorio de Vizcaya Licenciado Juan do Valle de Villena

Esta limitación y control de la venta de armas a extranjeros movilizó inmediatamente a los espaderos bilbaínos, recurriendo a la Chancillería. Una vez más queda de manifiesto la importancia que debió de tener para los artesanos bilbaínos el comercio de su producto con otros países, que les llevó a movilizarse rápidamente en contra de esta medida.

Las razones del Corregidor quedan expuestas en la notificación que se realizó a todos y cada uno de los espaderos de Bilbao, y gracias a la cual conocemos la población de estos artesanos en diciembre de 1569. Al parecer el Corregidor había recibido noticias de que algunos moriscos que diciendo ser mercaderes y con otras formas compraban gran cantidad de espadas. No podemos olvidar que en estas fechas está teniendo lugar el conflicto con los

\footnotetext{
45 Procede de la colección Pauilhac, a donde llegó desde la colección Estruch.

46 Mann, 1962: 312.

47 Dueñas, 2001

48 A.C.V. Sala de Vizcaya 1660-4. Leg. 712-4.
} 
moriscos que se produjo entre 1568-1570, y que desembocará pocos años después en su expulsión definitiva en 1611 con Felipe III.

No era nueva esta práctica de prohibir la posesión y venta de armas a poblaciones peligrosas para la corona. Pocos años después de la toma de Granada, el 3 de septiembre de 1501, los Reyes Católicos emitieron una orden ${ }^{49}$ contra los conversos jóvenes por la que:

ninguno de los dichos nuevamente convertidos de mozos no fueredes osados de traer armas algunas,...por primera vez pierda bienes y desterrado a perpetuidad, la segunda muerte

El Corregidor justifica su decisión ante su incapacidad para averiguar si eran ciertas estos rumores, y decidió que todos los maestros espaderos y los que fazen dagas no pudieran vender sus productos a nadie sin que antes dejaran testimonio ante escribano público de donde son naturales y su numero de licencia.

La justificación exacta de los motivos que le llevan al Corregidor a tomar semejante decisión es la siguiente:

Auto de nueve de diciembre de 1569 el corregidor dijo que había sido informado de que a esta villa de Bilbao acudían moriscos y bajo pretexto de ser mercaderes y con otras formas compraban y llevaban muchas espadas. Y aunque intentó realizar diligencias para averiguar la verdad y poner a ello remedio no había podido hacerlo. Por ello mando que se notificase a todos los maestres espaderos de la villa que no vendan espadas y los que hagan dagas ninguna daga a persona forastera sin que primero y ante escrivano declaren de donde son naturales y si licencia

Los espaderos de Bilbao reaccionaron presentando un testimonio en grado de apelación, ante la Sala de Vizcaya de la Chancillería de Valladolid siguiendo el proceso su curso. Argumentaban esta decisión en el hecho de que se sentían agraviados ya que:

tienen dada libertad para poder vender la mercaderia y espadas que labran en general e sin que se haya seguido daño y perjuycio alguno en general.

Alegaban a su favor los inconvenientes que les supondría tener que preguntar a cada forastero que llegara a su tienda su origen, lo que delata que debían de ser muchos. Justificaban esto de la siguiente manera:

que en hazer las diligencias en el dicho mandamiento contenidas se les pasaria el tiempo y no tenian de que se poder sustentar comodamente.

También proponen que se coloquen guardas que busquen a estos posibles compradores moriscos. Los espaderos trataron de defenderse explicando que no podían controlar quienes eran extranjeros o naturales, ni para donde las compraban, habiendo para eso otro tipo de controles.

y que para que no pasen las dichas armas, espadas y las de otro cualquier genero a rreynos estraños ny a fuera parte ay puestos guardas e casas de aduanas

Parece claro una vez más, y como tal lo entienden los espaderos, que el verdadero motivo de esta decisión es la de evitar que la producción de armas en Bilbao saliera fuera de las fronteras del imperio español. Lo que a su vez demuestra que la mayor parte de la producción de armas, y especialmente de espadas de Bilbao, tenía como fin la exportación.

Esta decisión se notificó a todos los espaderos y fabricantes de dagas de Bilbao uno a uno. El nombre y oficio de todos ellos aparece en un listado extraído del citado documento (consta como apéndice 1 al final del presente artículo) siendo éste uno de los puntos más

49 Pragmaticas y leyes recopiladas por los Reyes Católicos. Ley XII fol VI y ley CVI fol. IXX col. IIII capit. Fin. 

$m$ m.

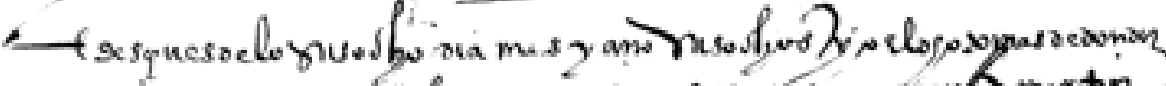

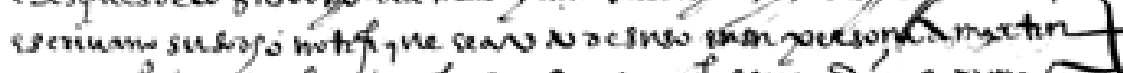

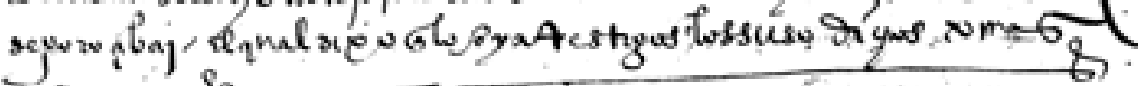
seonsiz 82

$$
\text { mint }
$$

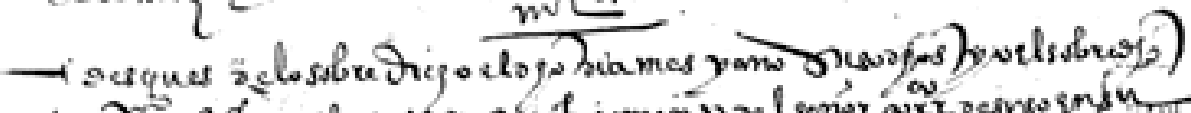

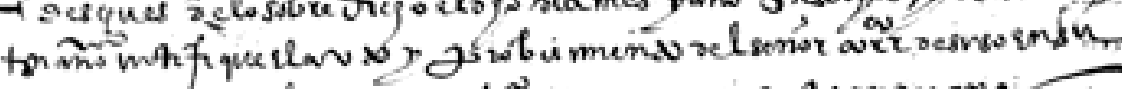

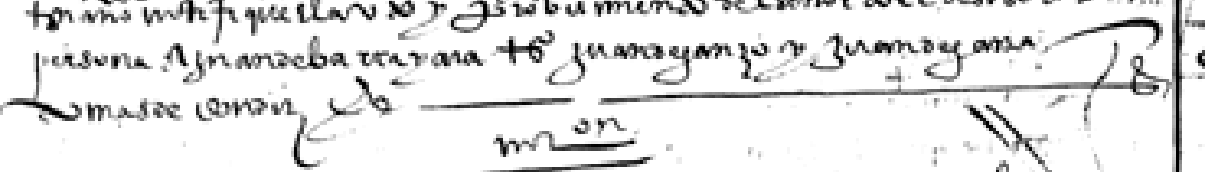

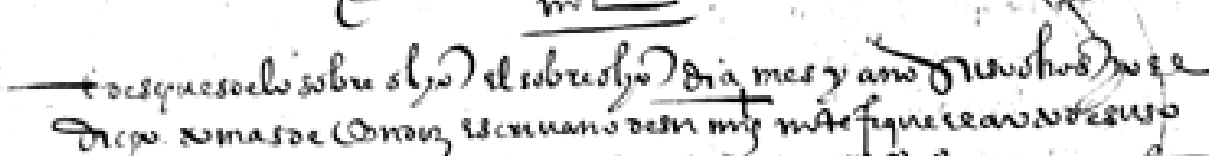

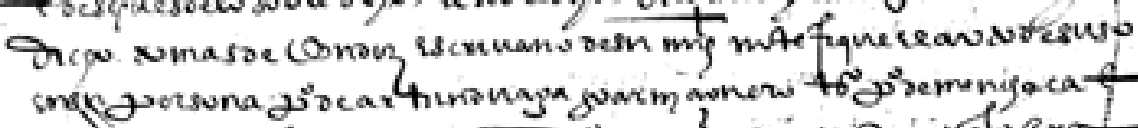

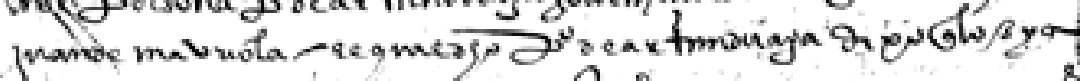

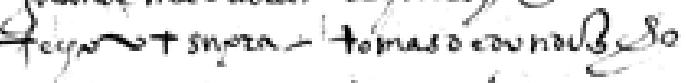

$2-\frac{2}{3}$ nutificain.<smiles>CCCCCCCC</smiles>
$\frac{\frac{1}{9}}{\frac{1}{9}}$

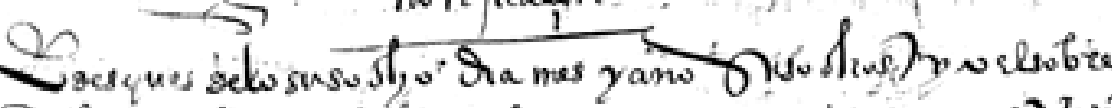

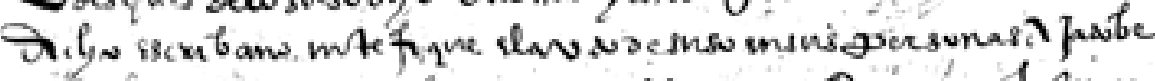

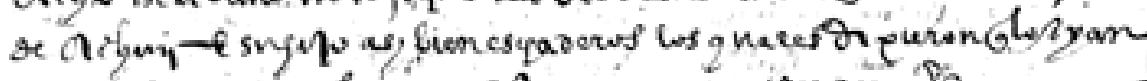

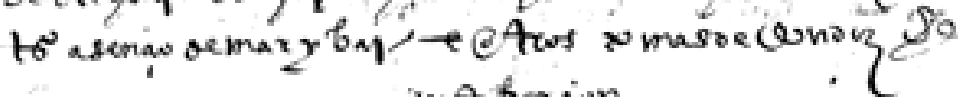

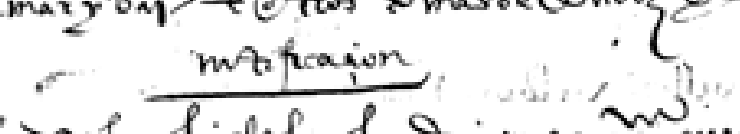

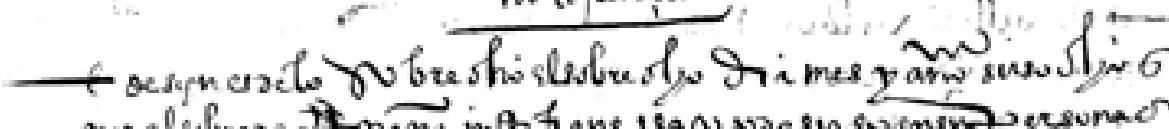

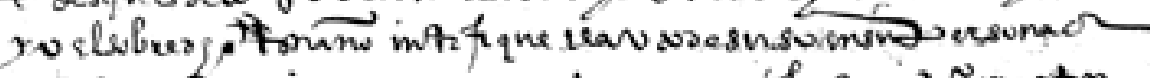

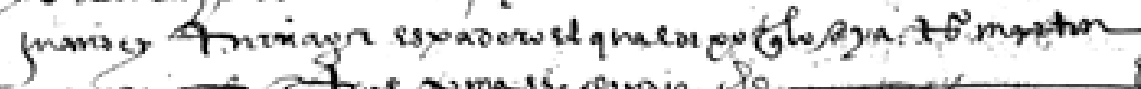

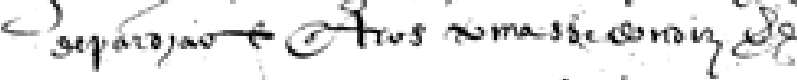

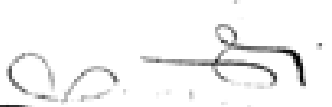

motificaion

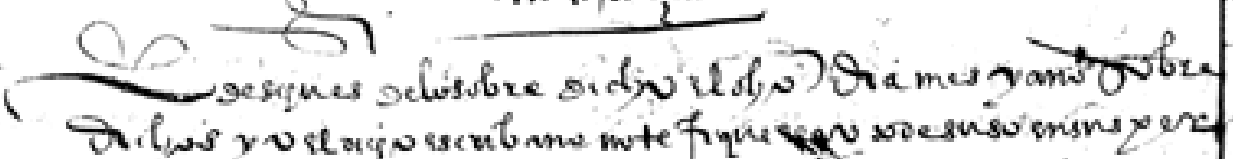

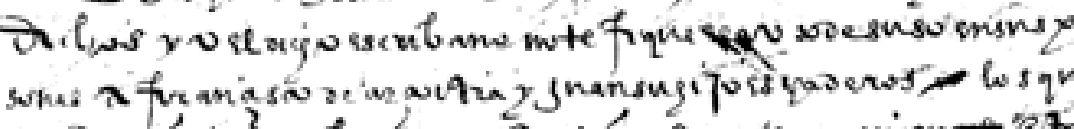

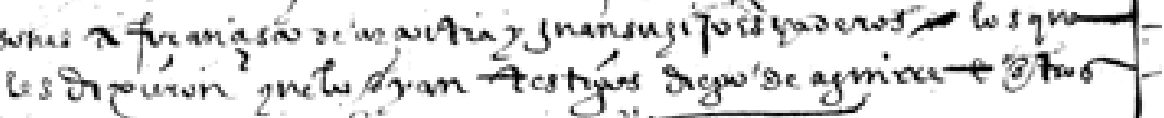

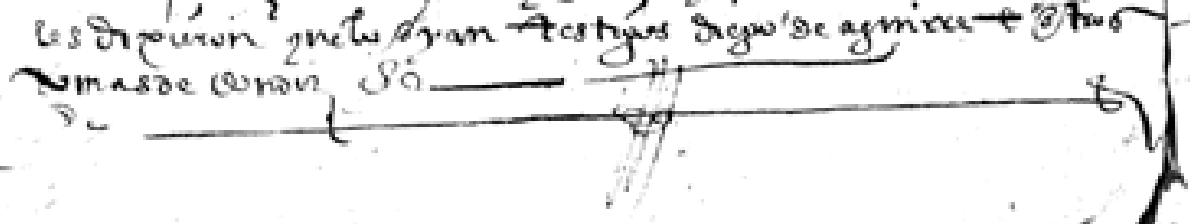

Fig. 4. Relación de algunos de los espaderos a los que el Corregidor de Vizcaya comunicó la decisión de controlar la venta de espadas a extranjeros en la ciudad de Bilbao a finales del año de 1569. 
interesantes para nosotros, ya que nos da una perfecta visión de la población espadera de la zona en 1569.

De todos ellos tenemos que destacar a un grupo que se denominan específicamente maestros espaderos de Bilbao, y que cabría diferenciar del resto que se trataría de oficiales, aprendices, e incluso algún comerciante no fabricante de espadas. Estos son Juan de Becurten, Jacobo y Juan de Achuri, Francisco de Azcoitia, Martin de Goroçibai, Juan de Barrayana, Martin de Zabala, Juan de Jauregui, Iñigo de Sertucha, Juan de Echabarria y Juan de Iturriaga.

Si comparamos estos nombres con los existentes en el Libro del Concejo de 1524 y con los del alarde de 1558 obtenemos una serie de datos muy interesantes. En primer lugar la presencia en los tres documentos de Juan de Becurten lo cual lo coloca como un importante y longevo espadero bilbaíno. Pensamos que se trata del mismo espadero, ya que su hijo Juan aparece también como espadero a la hora de la notificación de la orden del Corregidor.

Martín Goroçibay aparece en el primer y tercer documento, no así en el segundo. Esto parece indicar que no pudo participar en el alarde por algún motivo, o que el segundo fuera un descendiente que todavía no era maestro espadero en el momento de la realización del alarde. En el mismo caso está el apellido Azcoitia, Juan en el primero y Francisco y su hijo Juan en el tercero, siempre si seguimos la relación de nombres que Guiard nos ofrece del documento de 1524. El apellido Achuri en cambio aparece también en los tres documentos, como Martín Ochoa de Achuri en el primero, y Jacobo junto a su hijo Juan en los dos restantes.

Son más los espaderos que coinciden en los últimos dos documentos, ya que sólo son once los años que los separan 1558 y 1569: Martín de Zabala, Juan de Jauregui e Iñigo de Sertucha. Hernando de Gastaca aparecen en el Alarde y también entre los que reciben la notificación como espadero, aunque no entre la relación de maestros espaderos que aparecen como tales en el poder.

Parece claro que dentro del grupo de espaderos, de Bilbao había una serie de espaderos que tenían más peso, ya que aparecen constantemente en la documentación del proceso. Estos son fundamentalmente Francisco Azcoitia, Jacobo y Juán de Achuri y Juan de Becurten.

La palabra gremio no aparece citada, ni tampoco la de veedores, que eran los cargos gremiales que entre otras muchas misiones estaban encargados de representar al gremio en situaciones similares a la presente. Aunque esto no significa que no tuvieran un tipo de organización similar a la gremial con los mismos reglamentos y sistema de funcionamiento internos.

\section{CONCLUSIONES}

A pesar de los pocos estudios existentes son varios los centros productores de armas en la Península Ibérica durante el siglo XVI. Concretamente a la hora de fabricar espadas, y quizás eclipsados por la fama de una producción de calidad como la procedente de Toledo, no se tiene en cuenta la existencia de estos otros núcleos, como por ejemplo el bilbaíno.

La producción española de espadas se viene identificando tradicionalmente con la toledana. Normalmente se atribuye el origen hispano a piezas que poseen punzones en forma de escudetes coronados con iniciales, con espadas españolas. Descartando un posible origen español de otras ciudades como el caso de Zaragoza, con marcas en forma de cruces rellenas de cobre, caso de Julián del Rey. Más claro es el presente caso de los espaderos de Bilbao, donde y tal como se ha visto las marcas en forma de cruces son la totalidad de las hasta ahora conocidas.

La relación entre la producción de espadas en Bilbao y el mercado británico podría hacer pensar que algunas de las piezas albergadas en museos y colecciones inglesas puedan tener un origen diferente al hasta ahora asignado. Considerando las hojas por los punzones que presentan procedentes fabricadas en Alemania o Italia, países en los que varios de sus espaderos usaron diversos tipos de cruces. 


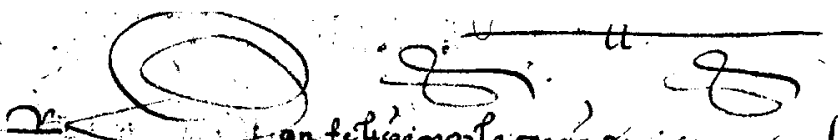

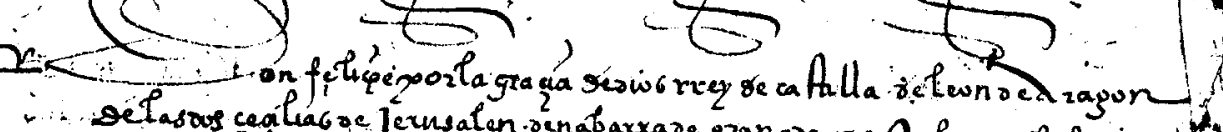

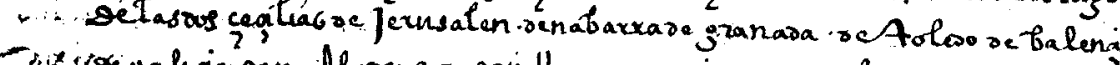

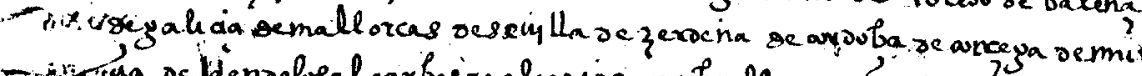

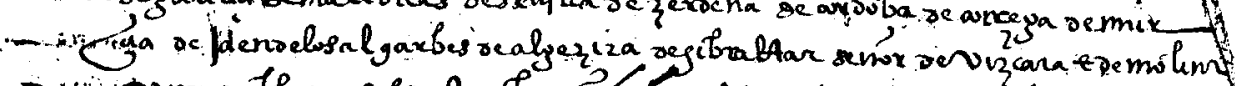

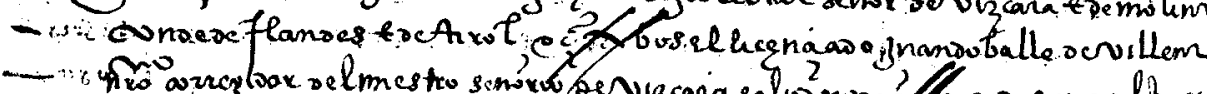

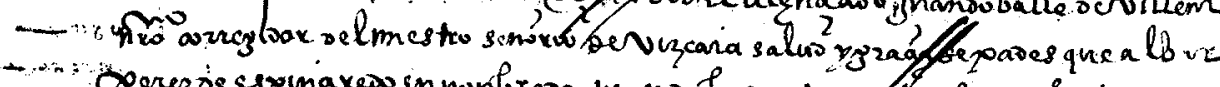

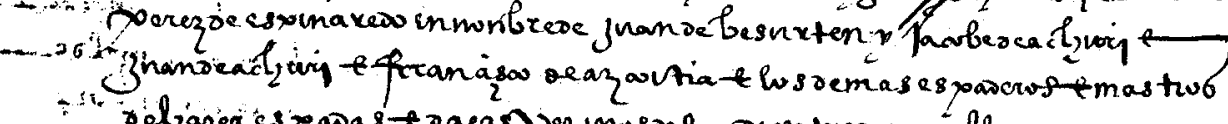

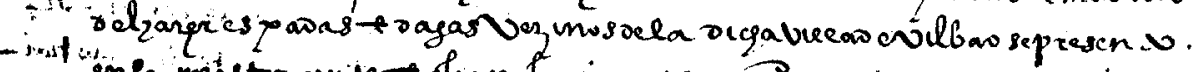

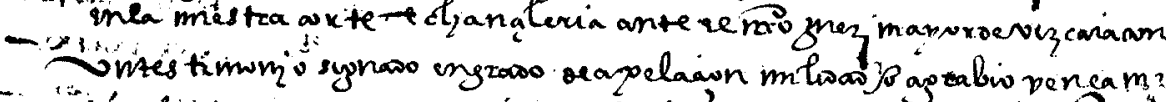

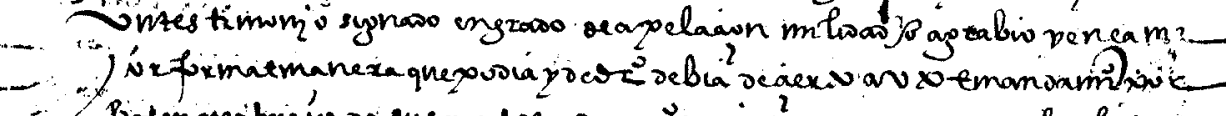

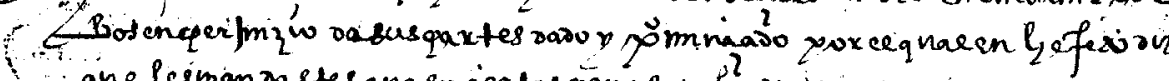

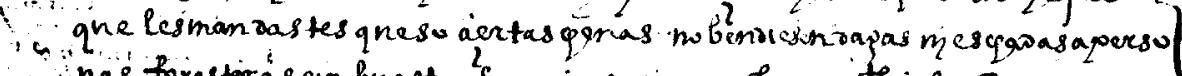

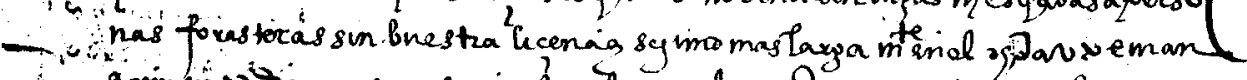

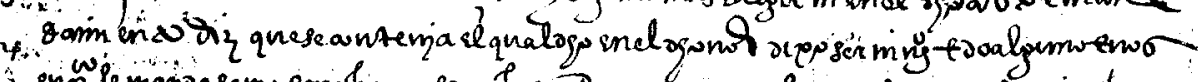

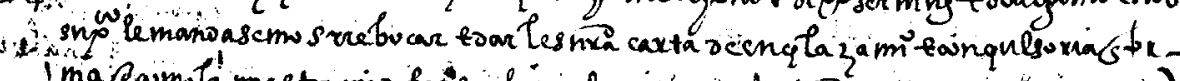

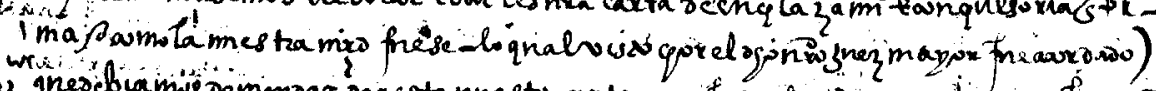

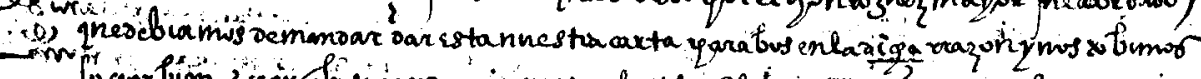

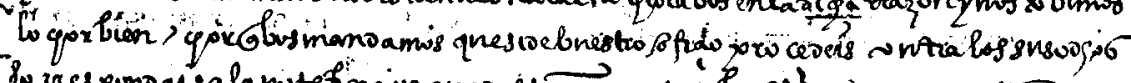

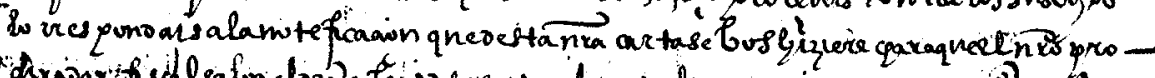

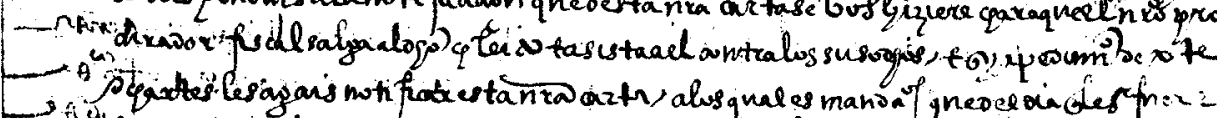

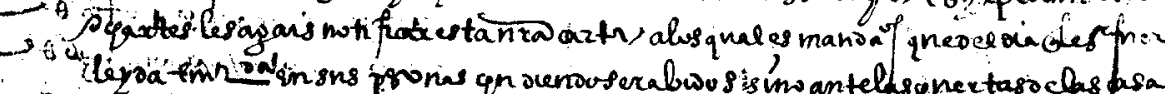

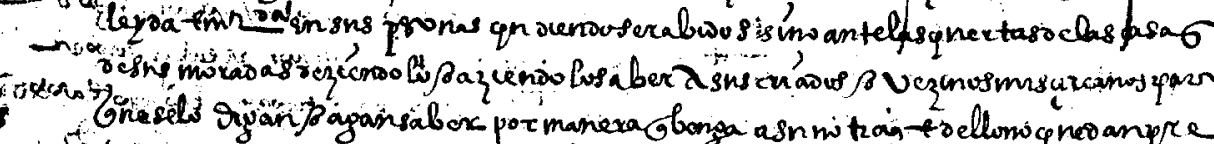

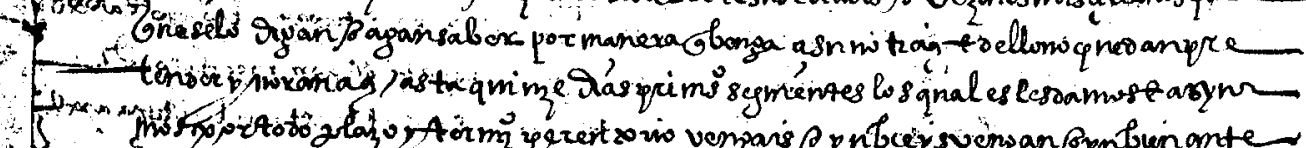

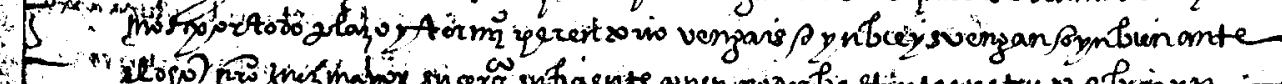

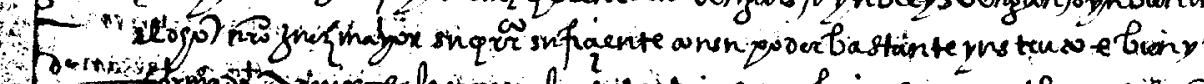

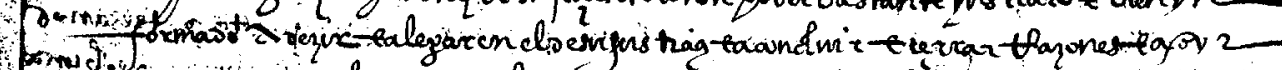

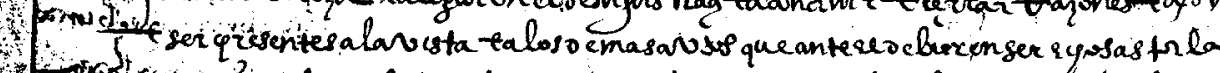

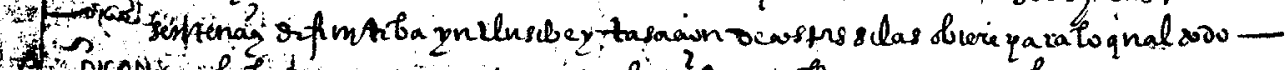

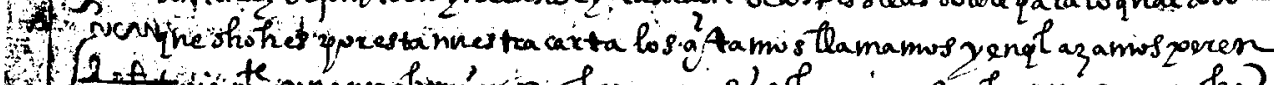

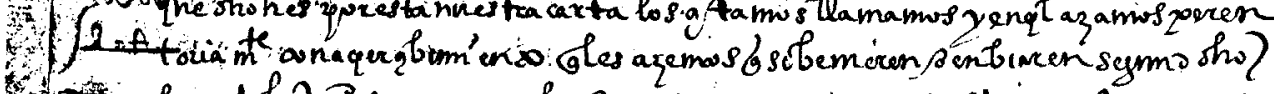

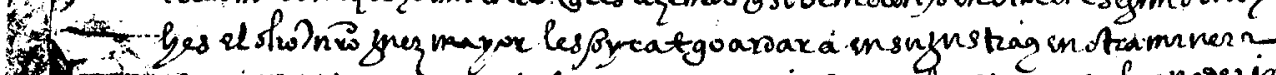

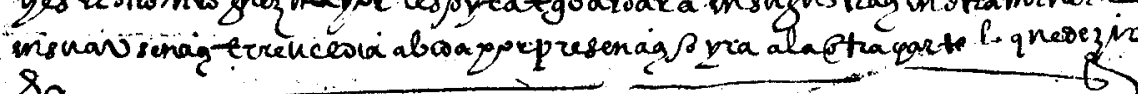
89 
Por todo ello la identificación de marcas y de los nombres de los espaderos que trabajaron en Bilbao puede resultar interesante de cara a una identificación más precisa de algunas hojas. Hasta el momento sólo poseemos diez marcas de otros tantos espaderos en una fecha tan temprana como 1524.

El hecho de que estos punzones eran elementos muy valorados, y que se heredaban como un derecho más, nos lleva a pensar que estas mismas marcas o variantes de las mismas serían las utilizadas durante todo el siglo XVI y XVII por los descendientes de estos artesanos o por los aprendices y oficiales más cualificados del taller del maestro principal.

El número de nombres de espaderos aquí recogidos es mayor que el de las marcas. También el marco cronológico es más amplio ya que abarca prácticamente todo el siglo XVI. En el caso de que estos artesanos hubieran tenido la costumbre de firmar sus hojas, tal y como lo hacían en otros centros especialmente en Toledo, nos permitiría identificar un mayor número de piezas. Pensamos que aunque no fue una práctica generalizada, sí que lo hicieron en algunos casos, ya que existen varios espaderos a los que conocemos gracias a que sus nombres aparecen inscritos en hojas de espadas, y que se corresponden a alguno de los aquí expuestos. Esta posibilidad se ve favorecida por lo fácilmente que se pueden identificar los apellidos vascos, especialmente los toponímicos.

Respecto al pleito entre el Corregidor de Bilbao y los artesanos bilbaínos pensamos que tiene varias explicaciones posibles. Lo que está claro es que hay un intento de controlar el comercio de armas por parte del representante de la corona en Bilbao. Las motivaciones fiscales, aunque posibles, nos parecen de poco peso, existiendo otros sistemas de control del citado comercio más efectivos.

El Corregidor de Bilbao justificó el control de las ventas de los espaderos en el hecho de que los moriscos se aprovisionaran de armas. Parece una medida lógica de cara a prevenir un ataque interno, especialmente en el contexto histórico en que se produjo. A pesar de ello creemos que, una vez más, se utilizó a los moriscos como excusa para justificar ese sometimiento de la producción a los poderes reales.

Quizás otro motivo más probable, sería el de evitar que esas armas cayeran en manos de un enemigo más poderoso como era Inglaterra. La relación del comercio entre Bilbao e Inglaterra tanto en materias primas como en productos manufacturados es clara, incluida la de espadas.

Podemos pensar que la dependencia que de estas manufacturas tenía la corona hispana por aquellos tiempos provocó la necesidad del control del tráfico y exportación de este y otros tipos de armas. Para ello la corona no dudaba en adoptar cualquier tipo de decisiones encaminadas a controlar la salida de armas o materias primas fabricadas en la zona vasca.

Ya en noviembre de 1488 los Reyes Católicos mandan a través de una Carta Patente, que no se puedan sacar armas del Condado de Vizcaya y de la Provincia de Guipúzcoa fuera de sus reinos ${ }^{50}$.

Carta Real Patente mandando que ni de la Provincia de Guipúzcoa, ni del condado de Vizcaya se saquen armas para afuera de estos reinos.

Queda impresa en el negociado de Vizcaya con el número LII, Tomo I, fol. 192

19 de noviembre de 1488

Don Fernando e Doña Isabel... nos somos informados que algunas personas vecinos e moradores desa dicha villa ( ríos bombardas e pasavolantes, e cerbatanas e espingardas, e ballestas e saetas, e lanzas e corazas, e pabeses, e capacetes e celadas e baneras (baveras), e otras armas contra el defendimiento que nos tenemos mandado poner en todos nuestros reynos e señorios: e porque sobre los tales levadores de armas e artillería nos entendemos haser la pesquisa e sabida la verdad mandar esecutar en ellos e en sus bienes las penas en que asi han e hobieren caído sobre esta razón, sobre lo cual mandamos dar esta nuestra dicha carta para

50 Ibidem, Op. Cit. Documento Num. XXXV, pág. 105. 
vosotros en la dicha rasón por la qual nos mandamos que... de que aquí en adelante persona ni personas algunas no sean osados de sacar nin llevar las dichas armas e artillería para fuera de los dichos reinos e señoríos...

Esta medidas se repetirían en adelante, acabando no sólo con la exportación de armamento, sino sobre todo de las materias primas con las que se elaboraban como el hierro, el acero, el carbón, etc. Así lo dejan también de manifiesto en una provisión del consejo, de mayo de $1539^{51}$ :

«El metal más necesario que tienen estos reinos nos es el fierro y el acero, y en Vizcaya y en las montañas donde hay la mejor abundancia de ello se van acabando los mineros porque se saca mucha vena para los reinos de Francia e de otras partes en tanto grado que si no se remedia en 10 años se acabarán los mineros y valdría mucho dinero el fierro y el acero y no se podría haber sino con dificultad; e por sacar la dicha vena se deja sin mantener muchos naturales de estos reinos que se sostienen de labrarla, e faser carbón para esto...e....otros dapnos; y en el fuero de Vizcaya que es confirmado por vuestra magestad se proveyó que no se sacase de estos reinos; suplicamos a vuestra magestad porque la guarda de esto es muy conveniente y necesario mande que se guarde el Fuero de Vizcaya en el capítulo que de esto fabla e poner mayores penas contra los transgresores-

A esto vos respondemos que nos hemos mandado que durante la guerra no se saque vena e para delante mientras otra cosa se mande mandamos lo mismo-

Asimismo suplicamos a vuestra magestad mande que la prohibición de sacar vena que tiene prohibida en las cortes últimas de Valladolid se guarde e vaya adelante por la notoria por la notoria utilidad que de ello a estos reinos se sigue

A esto vos respondemos que se guarde la ley que cerca dello dispone

Registro General de sello en el Real Archivo de Simancas, 13 mes de mayo año de 1539

Pero parece ser que lo mismo que sucedía con las armas respecto del incumplimiento de estas pragmáticas, sucedía respecto a este tipo de materias primas. Por ello se solicita por parte del representante de la ciudad de Segura ${ }^{52}$.

Y agora Martín Perez de Segura, en nombre de la dicha provincia de Segura nos suplicó que porque muchas personas contra lo contenido en los dichos capítulos de cortes sacan de estos nuestros reinos vena de hierro e acero para fuera dellos, le mandásemos dar nuestra carta insertos en ella los dichos capítulos para que aquellos fuesen guardados e cumplidos e procediesedes contra las tales personas, e los castigasedes oi como la nuestra merced fuese: lo cual visto por los del nuestro Consejo fue acordado que debiamos mandar esta nuestra carta para vos en la dicha razón e nos tovimoslo por bien: porque vos mandamos a todos e a cada uno de vos segund dicho es, que veais los dichos capítulos que de suso van incorporados, e los guardeis, cumplais y ejecuteis, e hagais guardar e cumplir y egecutar en todo y por todo según e como en ellos se contiene e contra el tenor e forma dellos no vais ni paseis, ni consisntais ir ni pasar en tiempo alguno, ni por alguna manera; e los unos y los otros non fagades nin faga ende al, so pena de la nuestra merced e de 10 mil maravedis para la nuestra cámara. Dad en la cibdad de Toledo a trese dias del mes de mayo de 1539 años-Cardenal-Corral-Escudero-Alava-Mercado-Alderete-Martín de Vergara.

Concuerda con el registro original. Está rubricado

En principio estas medidas afectaban al material susceptible de ser utilizado con fines bélicos, y se referían a aquellos países con los cuales se estuviese en guerra. Después y debido a la necesidad que de ellos se tenía, se tomó con carácter general. La frecuente documentación relacionada con este tema, parece indicar el fracaso de tales medidas debido al contrabando de estas y otras materias vedadas, con las que se seguía comerciando.

Resulta curioso comprobar como a comienzos del siglo XVII, concretamente en 1623, se sucede la situación contraria. La ciudad de Tolosa pide a la corona que se prohiba la entrada de armas fabricadas en el exterior, y que al parecer causó una grave crisis en la demanda de

51 Ibidem. Documento Num. XCIII, pág. 356.

52 Ibidem. Documento Num. LXXXVI, pág. 304. 
la producción que afectó a los talleres de armas blancas situados en la zona del Señorío de Vizcaya y de Tolosa ${ }^{53}$.

...se suplique el prohibimiento y entrada de las armas extranjeras en estos Reinos de España, y particularmente por hojas de espadas, montantes, alfanges, dagas, cuchillos y tijeras, porque esto es en muy notable agravio y perjuicios de los naturales, de tal forma que de mucha cantidad de fraguas, maestros y oficiales que se ocupaban en este ministerio asi en esta provincia como en el Señorio de Vizcaya

La zona vasca como centro productor de armas era vital para la política del Imperio español, y no se podía permitir que además se canalizara parte de esa producción al principal enemigo, Inglaterra.

53 Larrañaga, Op.Cit.: 390. 


\section{APÉNDICE}

Documento 1

Nómina de espaderos bilbaínos por orden alfabético y cronológico entresacados de los documentos aquí estudiados

Nombres de espaderos citados en un contrato realizado en 1519 por Areitio

Martin de Gorosabel

Juan de Ceberio

Relación de espaderos que aparecen junto a sus marcas en el Libro del Concejo de Bilbao de 1524

Domingo de Azcoitia (Según Areitio)

Domingo de Alcorta y Juan de Azcoitia (Según Guiard)

Juan de Beaduren o Besurten

Juan de Olagorta

Juan de Vidaguren

Martin de Gorocibay

Martin de Mantulis

Martin de Ugarte

Martin Ochoa de Achuri

Pedro de Zamudio

Relación de espaderos que aparecen en el alarde de 1558

Anton de Ereño

Francisco de Azpeitia

Hernando de Gastaca

Iñigo de Sertucha

Jacobo de Achuri

Juan de Baquio

Juan de Barrancu

Juan de Becurten o Besurten

Juan de Bolumburu

Juan de Jauregui

Martin de Izcoa

Martin de Zabala

Pedro de Urizar

Relación de espaderos que aparecen en el pleito sostenido con el Corregidor de Vizcaya

Diego Marques

Esteban de Landaeta- Daguero

Francisco de Azcoitia y su hijo Juan

Francisco de la Tienda (citado junto a Jacobo de Mendieta)

Hernando de Gastaca y su hijo Hernando

Iñigo de Sertucha

Jacobo de Achuri

Jacobo de Mendieta (citado junto a Francisco de la Tienda)

Juan de Achuri

Juan de Barrayana 
Juan de Besurten y su hijo Juan

Juan de Echavarria

Juan de Gorocibay

Juan de Jauregui

Juan de Vidaguren

Juan de Yturriaga

Juan Santibañez (citado junto a Martín de Olea)

Justino de Mendieta

Martin de Igueldo?

Martin de (ilegible)

Martin de Gorocibay

Martin de Olea (citado junto a Juan Santibañez)

Martin de Zabala

Mateo de Sertucha

Pedro de Artonduaga- guarnicionero

Sancho de Jaureguizar- guarnicionero

Sancho de Palacios

Dentro del pleito en un poder de los espaderos se cita una relación más breve de Maestros espaderos

Francisco de Azcoitia

Iñigo de Sertucha

Jacobo de Achuri

Juan de Achuri

Juan de Barrayana

Juan de Besurten

Juan de Echabarria

Juan de Iturriaga

Juan de Jauregui

Martin de Gorocibay

Martin de Zabala

GERMÁn DueÑas BERAIZ

Rafael Finat, 64 - $4^{\circ}$ Izquierda - 28040. Madrid

\section{BIBLIOGRAFÍA}

A.A.V.V. (1975): Enciclopedia General Ilustrada del Pais Vasco. Auñamendi. San Sebastián.

A.A.V.V. (1984): Ordenanzas municipales de Bilbao de 1593. Fuentes Documentales. Ayuntamiento de Bilbao.

AREITIO, D. (1959): Los vascos en la historia de España. Bilbao

Boccia, L. G.; Godoy, J. A. (1986): Musei e gallerie di Milano. Museo Poldi-Pezzoli. Armeria. Electra edizioni. Milano.

Colección de Documentos Inéditos para la Historia de España T. 46-96-97. Imprenta de la viuda de Calero. Madrid, 1842-1864.

DuEÑAs BeraiZ, G. (2000): «Julián del Rey: Nuevos datos sobre su figura». Gladius, XX: 269-284. 
Dueñas Beraiz, G. (1999): Los gremios de espaderos españoles en la Península Ibérica (S. XVI$X V I I$ ). Aproximación a su estudio (Grado de Salamanca inédito). Departamento de Historia Moderna, Medieval y Contemporánea. Universidad de Salamanca.

DueÑas Beraiz, G. (2001): «La colección de armería e historia militar del Museo San Telmo de San Sebastián». Militaria. Revista de Cultura Militar, (en prensa).

FfoulKes, C. (1916): The Armouries of the Tower of London (2 vol.). His Majesty's Stationary Office. London

FFOULKES, C. (1912): The armourer and his Craft. London

Gestoso y Perez, J.: (1899): Las industrias artísticas en Sevilla. Madrid GonZalez, T. (1829): Colección de cédulas, cartas-patentes, provisiones, reales órdenes y otros documentos concernientes a las provincias vascongadas copiadas por orden de S.M. de los Registros, minutas y escrituras existentes en el Real Archivo de Simancas y en los de las Secretarías de estado y del despacho y otras oficinas de la corte. Madrid,.

Guiard Larrauri, T. (1905): Historia de la Muy Noble Villa de Bilbao. Bilbao

GUIARD LARRAURI, T. (1908): Historia del consulado de Bilbao. Bilbao

HALE, J.R (1985).: Guerra y Sociedad en la Europa del Renacimiento (1450-1620). Ministerio de Defensa - Secretaría General Técnica, Madrid.

LaRrañaga, R. (1981): Síntesis Histórica de la Armería Vasca. Caja de Ahorros Provincial de Guipúzcoa, San Sebastián.

LEGARDA, A. (1953): Lo vizcaino en la literatura castellana. Biblioteca de la RSVAP. Bilbao.

LEGUINA, E. (1897): Los maestros espaderos. Sevilla.

Leguina, E. (1908): Las espadas de Carlos V. Madrid.

LEGUINA, E. (1912): Glosario de voces de armería. Madrid.

ManN, J. (1962): Wallace Collection Catalogue. European Arms and Armour. (II vol.). The trustees of the Wallace Collection. London

MiLlER, Y. A. (1995): «Les armes anciennes espagnoles de 1'Hermitage». Militaria. Revista de Cultura Militar. Número 7: 187.

MugICA, G. (1910): Eibar, monografía histórica. Irún.

OAKESHOTT, E. (1980): European weapons and armour. Suffolk.

Pragmáticas y Leyes Recopiladas (...) por los Reyes Católicos. Medina del Campo, 1549.

REID, W. (1976): The Lore of arms. Ghotemburg.

SAN VICENTE PINO, A. (1988): Instrumentos para una historia social y económica del trabajo en Zaragoza en los siglos XV-XVIII. Real Sociedad Económica Aragonesa de Amigos del País. Zaragoza. 